\title{
Analysis of the Association of Selected Leisure Time Activities and Overweight in University Students
}

K. Grendova (Kristina Grendova), M. Machajova (Michaela Machajova), K. Bartkova (Klaudia Bartkova)

Trnava University, Faculty of Health Sciences and Social Work, Department Original Article of Public Health SK.

\section{E-mail address:}

kristina.grendova@truni.sk

\section{Reprint address:}

Kristina Grendova

Department of Public Health

Faculty of Health Sciences and Social Work

Trnava University in Trnava

Univerzitne nam. 1

91843 Trnava

Slovakia

Source: Clinical Social Work and Health Intervention

Volume: 12

Issue: 5

Pages: 29 - 35

Cited references: 14

\section{Reviewers:}

Johnson Nzau Mavole

Catholic university of Eastern Africa, Nairobi, KE

Jirina Kafkova

MSF, Freetown, SL

\section{Keywords:}

Free Time Activities. Adolescents. Overweight. Obesity. Primary Prevention.

\section{Publisher:}

International Society of Applied Preventive Medicine i-gap

CSWHI 2021; 12(5): 29 - 35; DOI: 10.22359/cswhi_12_5_04 (C) Clinical Social Work and Health Intervention

\section{Abstract:}

Objective: The aim was to analyze preferred free time activities of adolescents / university students

Design: Cross-sectional study

Participants: The inclusion criteria for participants were fulltime university students with a maximum age of 25 years. The study involved a total of 173 students.

Methodology: Data were collected by an online questionnaire and also by observing the behavior of university students. The obtained data were processed in the statistical program R-project. Statistically significant values are at the level of $\mathrm{p} \leq 0.05$. Statistical tests - chi square test and correlation - were used for the analysis. 
Results: The results show that university students prefer sedentary activities in their free time, the prevalence of overweight and obesity is increasing. University students spend several hours a day in front of their computer screen.

Conclusion: The results proved that smoking had no effect on BMI values. The results showed that there was no statistically significant difference in BMI values in terms of the amount of time university students spend in front of their computer screen in their free time.

\section{Introduction}

Adolescence brings new opportunities and at the same time new risks to young people. The habits of young adults can have both, positive and negative effects on health. The influence of society and the media such as the internet, television, radio, the press and others affect the lives of young people and can influence them. The most popular form of spending free time for adolescents is on the media. Adolescents' leisure time is one of the public health problems. In the $21 \mathrm{st}$ century, the importance of leisure time was defined by documents and activities adopted in the previous century. Leisure time is one of the most important sources of personal, social and economic development that contributes significantly to the quality of life. Leisure time promotes overall health and well-being. Society is a complex and interconnected system and leisure time cannot be separated from other life goals. Nowadays, growing dissatisfaction; stress; boredom; lack of exercise; loss of creativity; alienation are characteristic for many societies. All these problems can be reduced through leisure activities. One should spend at least 150 minutes a week on moderate-intensity physical activity or 75 minutes on high-intensity physical activity (the intensity of activity can also be adequately combined). Aerobic exercise should always last at least 10 minutes and at least 2 days a week should be devoted to strengthening the main muscle groups ("Global Recommendations", 2010). Leisure time is above all a time "for yourself" and your loved ones. This time is stated to be devoted mainly to hobbies, friends and family, or simply to "doing nothing".

\section{Theoretical Background}

A study by authors Matejovicova et al. showed that drug use is increasing at university, especially among girls. The results showed the use of illegal drugs if their parents were university-educated (2015).

Tobacco and alcohol are legal, easily available and socially tolerated substances that are also part of this issue. The increase began in 2008, especially among young women. If we compare the results in drug use among young women and young men, women reach the same level of drug use as men (Nociar, 2014).

Physical activity that young people do in their free time is necessary for further development, especially for university students for whom this activity is important not only for mental, but also for physical development. At the same time, leisure time is a risk factor if it becomes unstructured and unorganized by the student (Ilieva, Ignatov, 2017).

A high prevalence of risk factors for cardiovascular diseases has been found in the population of young people, especially in university students. These factors included overweight, in $27.5 \%$ of male students; $7.1 \%$ of female students. Visceral obesity was found in $15.2 \%$ of female students; $10,1 \%$ of male students. The results also indicate low physical activity, which is one of the other factors in the development of cardiovascular diseases, in $41.9 \%$ of female students; $31.9 \%$ of male students. Of the respondents, $22.1 \%$ of male students; $10 \%$ of female students were current smokers (Illow, Rozanska, Illow, 2016).

The majority of European full-time students $(75 \%)$ who were involved in the research devote their free time to work in addition to university studies as confirmed by a comparative analysis of the social and economic living conditions of university students in Europe with an emphasis on results for the Slovak Republic. The largest share of working students (more than $60 \%$ ) is in Ireland, the Netherlands, the Czech Republic, Es- 
tonia, Switzerland, Malta, Poland and Austria. Norway, Germany, Denmark, Finland, Sweden, Montenegro, Hungary, Latvia, Croatia and France are countries with a medium share of working students (40\% to $60 \%$ ). Less than $40 \%$ of students work in countries including Romania, Russia, Italy, Georgia, Ukraine, Serbia, Lithuania, Bosnia and Herzegovina and Armenia (EUROSTUDENT, 2015).

\section{Objectives}

The aim of the study was an analysis of leisure activities and overweight in university students.

To achieve it, we chose sub-aims: to find out the eating habits of university students; to find out the prevalence of smoking among university students; to find out the amount of time they spent in front of their screen; to analyze the frequency of physical activity in their free time.

We set hypotheses:

1. We assume that there is no statistically significant difference in the value of BMI depending on the performance of physical activity in leisure time.

2. We assume that there is a statistically significant difference in the performance of physical activity in leisure time depending on gender.

3. We assume that there is a statistically significant difference in BMI values depending on the time that university students spend in front of the screen in their free time.

4. We assume that there is no statistically significant difference in cigarette smoking depending on gender.

\section{Monitor Research Sample Group and Methodology}

A cross-sectional study was conducted among university students between September 2020 and January 2021. The questionnaire survey was conducted using an online platform, as the epidemiological situation did not allow other methods of data collection. The condition for inclusion was that the respondents were full-time university students and at the same time did not exceed the age of 25 . We used an online questionnaire which was filled in by 173 students. The questionnaire consisted of 12 questions. The $1^{\text {st }}$ part consisted of questions aimed at finding general data about the respondents. The 2 nd part consisted of questions to identify leisure activities that affect the development of overweight or obesity in the monitored population of university students. The questionnaires were sent to the respondents by e-mail, and there was also a link allowing filling in on a telephone or computer available. Students were informed that filling in was voluntary and anonymous. The return rate of the questionnaires was $87 \%$. Obtained data were processed using a statistical program R-project and then interpreted in the paper. In statistical analyzes, we considered statistically significant values at the level of $p \leq 0.05$. Statistical tests - chi square test and correlation - were used for the analysis.

\section{Results}

The majority of university students (92\%) stated that they did not eat regularly, which could affect their body weight. In the work, we did not identify the factors that affect the regularity of eating. The causes can be: lack of time; lack of funds; lack of options; short lunch breaks. In the next question, we were interested in students' opinion on whether they considered their diet to be balanced. $8 \%$ of women; $2 \%$ of men considered their diet balanced. "Rather yes" was stated by $35 \%$ of women; $15 \%$ of men. The "rather no" answer was chosen by $7 \%$ of women; $26 \%$ of men. For $8 \%$ of men; $6 \%$ of women, their diet was definitely not balanced.

$92 \%$ of the surveyed university students agreed with the statement that society influences our lifestyle which points to the formation and selection of leisure activities according to what is interesting; what the society appreciates; what the trends are. Especially for young people, such information is a warning sign as some of these trends may have negative impact on young people's health. The findings show that $45 \%$ of the university students who participated in the research had the BMI value higher than 25; $43 \%$ of the university students involved in the research had the standard value of $18.5-25 ; 12 \%$ of the students had BMI values below 18.5.

Prevalence of smoking in the monitored group represented $14 \%$ of the university students smoking regularly. $20 \%$ of the university students smoke occasionally; $66 \%$ of the university students do not smoke. Using the chi square test, we 
confirmed the hypothesis that there is no statistically significant difference in BMI according to the frequency of smoking ( $>00.05)$. In the sample group, according to gender, $19 \%$ of women; $12 \%$ of men smoke. $81 \%$ of women; $88 \%$ of men chose the answer "do not smoke". Using the chi square test, we confirmed the hypothesis that there is no statistically significant difference in cigarette smoking according to gender $(p>0.05)$. Using a chi square test, we refuted the hypothesis that there was a statistically significant difference in BMI values according to the time that university students spend in front of the screen in their free time $(\mathrm{p}>0.05)$.

$57 \%$ of the university students perform physical activity in their free time at least once a week; $30 \%$ of the university students perform physical activity at least once a month; $23 \%$ of the university students stated that they did not do sports in their free time. Using the chi-square test, we confirmed the hypothesis that there was a statistically significant difference in the performance of free time physical activity according to gender $(\mathrm{p}>0.05)$.

On average, university students spend 5.5 hours a day in front of a screen, including a telephone or computer. It is only the time that is used in this way in their free time. $14 \%$ of the university students spend less than 2 hours a day in front of the screen; $59 \%$ of the students spend in front of the screen 2-3 hours of their free time per day; $27 \% 3$ hours a day. Using the chi square test, we verified the hypothesis that there was no statistically significant difference in BMI value and performing physical activity in leisure time $(\mathrm{p}>0.05)$.

We focused on the preferred leisure activities which we assigned to individual categories according to the BMI value. Respondents could choose several answers on how they spend their free time. Respondents whose BMI value was below 18 were mainly engaged in PC activities in their free time $95 \%$ of them chose this answer; $53 \%$ do sports; $47 \%$ devote their free time to reading; $42 \%$ of the respondents chose going to cinema and theater. $37 \%$ of the respondents with BMI value lower than 18 spend their free time watching TV; $26 \%$ of the respondents with BMI value below 18 go out to socialize. The largest percentage of the students with BMI value between 18 and 25: 87\% prefer various activities that they perform on $\mathrm{PC}$ in their free time; 59\% of the respondents with BMI value between 18 and 25 prefer watching TV in their free time, $55 \%$ said that in their free time they go out with friends; $54 \%$ read various literature; the same percentage, $54 \%$ devote their free time to sports activities. At least $38 \%$ of the students go to a cinema or theater in their free time. Students with BMI value higher than 25 prefer activities on a computer in their free time; $84 \%$ chose this answer. $53 \%$ of the students with BMI value higher than 25 likes to read books and the same amount; $53 \%$, go out to socialize; $51 \%$ enjoy sports activities; the same amount, $51 \%$, watch $\mathrm{TV}$ in their free time. $41 \%$ of this category go to a cinema or theater (Table 1).

Table 1 Selected activities according to BMI value

\begin{tabular}{|c|c|c|c|c|c|c|}
\hline $\begin{array}{c}\text { Answer } \\
\text { options }\end{array}$ & $\begin{array}{c}\text { BMI } \\
\text { under } \\
18\end{array}$ & $\begin{array}{c}\text { BMI } \\
\text { of } \\
18-25\end{array}$ & $\%$ & $\begin{array}{c}\text { BMI } \\
\text { above } \\
25\end{array}$ & $\%$ \\
\hline Reading & 9 & 47 & 41 & 54 & 41 & 53 \\
\hline $\begin{array}{c}\text { Watching } \\
\text { TV }\end{array}$ & 7 & 37 & 45 & 59 & 39 & 51 \\
\hline $\begin{array}{c}\text { Activities } \\
\text { on } \\
\text { computer }\end{array}$ & 18 & 95 & 66 & 87 & 65 & 84 \\
\hline $\begin{array}{c}\text { Going } \\
\text { out - } \\
\text { socializing }\end{array}$ & 5 & 26 & 42 & 55 & 41 & 53 \\
\hline $\begin{array}{c}\text { Cinema } \\
\text { and } \\
\text { theatre }\end{array}$ & 8 & 42 & 29 & 38 & 29 & 41 \\
\hline Sports & 10 & 53 & 41 & 54 & 39 & 51 \\
\hline
\end{tabular}

Out of the students with BMI value under 18: $21 \%$ do not do sports regularly; $53 \%$ do sports at least once a week; $26 \%$ do occasional sports which means that they engage in physical activity at least once a month. Students included in the category of BMI values ranging from 18 to 25 chose the option "I do not do sports" in 13\%; the majority, i.e. $61 \%$ do sports regularly; $26 \%$ of the respondents do sports occasionally. The 3rd category was students whose BMI value exceeds 25 : $10 \%$ of those respondents do not do sports at all; $53 \%$ do sports regularly; $37 \%$ occasionally. 
Table 2 Frequency of physical activity in leisure time according to BMI value

\begin{tabular}{|c|c|c|c|c|c|c|}
\hline $\begin{array}{c}\text { Answer } \\
\text { options }\end{array}$ & $\begin{array}{c}\text { BMI } \\
\text { under } \\
18\end{array}$ & $\begin{array}{c}\text { BMI } \\
\text { of } \\
\mathbf{1 8 - 2 5}\end{array}$ & $\begin{array}{c}\text { \% } \\
\text { above } \\
\mathbf{2 5}\end{array}$ & $\%$ \\
\hline $\begin{array}{c}\text { I do not } \\
\text { do sports }\end{array}$ & 4 & 21 & 10 & 13 & 8 & 10 \\
\hline $\begin{array}{c}\text { Regularly } \\
\text { (at least } \\
\text { once } \\
\text { a week) }\end{array}$ & 10 & 53 & 47 & 61 & 41 & 53 \\
\hline $\begin{array}{c}\text { Occasionally } \\
\text { (at least } \\
\text { once } \\
\text { a month) }\end{array}$ & 5 & 26 & 19 & 26 & 28 & 37 \\
\hline
\end{tabular}

\section{Discussion}

University students are a part of the population that needs to be given sufficient attention. It is important to address the factors that affect their leisure time, whether as risk factors or, conversely, protective factors during this age period. Most of the respondents reported irregularities in their eating habits. Slow metabolism is one of the consequences of irregular eating; the body slows down; the brain does not work at the level it should; the lungs, heart or other organs do not perform their function on $100 \%$. The body saves energy. If physical inactivity accompanies irregular eating, the body immediately begins to store the excess fat. Another common consequence of skipping meals is a lack of energy, which is accompanied by: fatigue; impaired concentration; irritability; or headaches. These symptoms are most often associated with irregular eating and blood glucose fluctuations. If one skips meals, their blood sugar level will fall sharply. Irregular eating or skipping meals usually leads to a lack of nutrients in the body. A body can function properly only if it has: the optimal amount of quality proteins; healthy fats; complex carbohydrates; vitamins; minerals; trace elements; other substances. These can only be provided by a regular and balanced diet. For example, calcium deficiency causes osteoporosis; low iron levels lead to anemia; avitaminosis $\mathrm{C}$ causes fatigue and immune disorders. $92 \%$ of the students agree with the statement that society influences their lifestyle. The media influences the choice of ac- tivities according to what is fashionable, often it being not entirely suitable for health; whether it goes in the direction of overweight or underweight; imitating an idol; gaining a perfect figure can escalate into anorexia or other eating disorders - binge eating. According to the findings, fast food is a popular form of eating. It's cheap and convenient. For many companies this strategy has paid off: more than 1 in 3 American adults consume fast food on a given day (CDC, 2020).

Many studies have focused on spending free time online, with a focus on university students. The most common reasons for using the internet and smartphones were: sending e-mails; sending messages; spending time on social networks; listening to music (Carbonell et al., 2018). A negative impact on university students' health was noted in students of medicine, pharmacy, and dental medicine in whom a significant relationship between potential internet addiction and anxiety, depression, and stress was found (Younes et al., 2016). A Planet Health study used secondary school classes: to support watching television; increasing activity; improving diet. Compared to the control group, students who were assigned a time limit on television had a lower incidence of obesity in girls (CDC, 2020). The frequency of overweight and physical inactivity increases with increasing screen time. A relationship between too much time spent in front of the screen and poor eating habits has been reported in adolescent girls (Christofaro. G.D.et al.). Insufficient physical activity is a significant risk factor for diseases of civilization (NCD) such as: stroke; diabetes; cancer; as well as for other cardiovascular diseases. The level of physical activity is on a declining trend in many countries. Overall, $23 \%$ of adults and $81 \%$ of school-age adolescents are not sufficiently active. Adequate activity should be part of everyday life. The WHO Global Action Plan for the Prevention and Control of the NCDs 2013-2020 expresses the motivation of the population for increased interest in physical activity. The goal is greater population activity to reduce the burden of NCDs, as expressed, the plan calls for a $10 \%$ reduction in physical inactivity by 2025 , which contributes to achieving the Sustainable Development Goals (SDGs).

The WHO has provided general recommendations for a minimum number of activities for 
all age groups to improve health; but it is important to know that doing some physical activity is better than doing none. Inactive people should start with a small amount of physical activity as part of their daily routine and gradually increase the duration, frequency and intensity. Start with a walk, light pace and increase the load accordingly. Countries and communities should also take targeted steps to provide individuals with opportunities to be physically active. Physical activity brings a number of health benefits; reduces the risk of coronary heart disease; stroke; diabetes; hypertension; depression; various types of cancer including colon cancer and breast cancer. It is the basis of energy balance and weight control. In general, women and girls are less active than men and boys; older adults are less active than younger adults. Adults aged 18 to 64 should achieve at least 150 minutes of moderate physical activity each week or at least 75 minutes of intense activity throughout the week, or an equivalent combination of mild and intense activity. To be beneficial for health and prevention of cardiovascular and respiratory diseases, each activity should be performed at intervals of at least 10 minutes (WHO, 2018).

According to a study from 2016, more boys than girls engage in physical activity in their free time (Telford et al., 2016). However, both sexes exercise the same amount of physical activity in their free time, $50 \%$. A study focused on the frequency of free time physical activity was conducted with 24-year-old adolescents. It found that $2.5 \%$ of the respondents perform physical activity in their free time several times a day; $11.6 \%$ perform physical activity every day. Physical activity was performed 4 times a week by $16.5 \%$ of the 24 years old respondent; twice a week by $33 \%$; once a week by $19 \%$; $1-2$ times a month by $9.3 \%$; less than once a month by $6.2 \%$; not at all by $2.1 \%$ (Aaltonen et al., 2016). Smoking does affect BMI value, so we focused on this issue as well. $14 \%$ of the university students smoke regularly; $20 \%$ of university students smoke occasionally; $66 \%$ of university students do not smoke. Using a statistical chi-square test, we refuted the hypothesis that there is a statistically significant difference in BMI values according to the time that university students spend in front of the screen in their free time, $p$ value $p>0.05$. As a result, increasing time spent in front of the screen does not increase BMI value, yet other factors are not considered. On average, university students spend 5.5 hours a day in front of a screen, including a telephone or computer. It is only the time that is used in this way in their free time. $14 \%$ of the university students spend less than 2 hours a day in front of the screen; $59 \%$ of the students spend in front of the screen 2-3 hours/day out of their free time; $27 \%$ of the students spend 3 hours a day.

\section{Conclusion}

Confirming or refuting hypotheses about the effect of smoking on BMI value was one of the goals of our work. By evaluating the questionnaire data from university surveys, the given hypothesis was refuted. The results clearly indicate that smoking does not affect BMI value. We focused on the hypothesis of whether there was a statistically significant difference in BMI values according to the time spent by university students in front of the screen in their free time. This hypothesis was refuted. The existence of various intervention programs helps to promote a balanced diet that university students lack. Low regular participation in physical activity in leisure time can lead to the definition of the basic objectives of the intervention. Society should pay more attention and create space for physical activity, either in the form of active involvement with children in these activities or by creating appropriate conditions and sufficient time for physical activity. It is necessary to focus on this issue on not only regionally but also on the state level. It is necessary to expand sports venues and provide as many opportunities for movement as possible. Current steps are affecting the future, and primary prevention is a key to reducing the risk of cardiovascular diseases.

\section{References}

1. AALTONEN S et al. (2016) Leisure-Time Physical Activity and Academic Performance: Cross-Lagged Associations from Adolescence to Young Adulthood. In Scientific reports. [online]. 2016. vol. 6, no. 39215. Available online: https://www.ncbi.nlm.nih.gov/ pmc/articles/PMC5156951/pdf/srep39215.pdf.

2. CARBONELL X et al. (2018) Problematic Use of the Internet and Smartphones in University Students: 2006-2017. In International 
Journal of Environmental Research and Public Health. [online]. 2018, vol. 15, no. 475. Available online: https://www.ncbi.nlm.nih. gov/pmc/articles/PMC5877020/pdf/ijerph15-00475.pdf.

3. CDC (2020) Health Effects of Cigarette Smoking. 2020. online. Available online: https://www.cdc.gov/tobacco/data_statistics/f act_sheets/health_effects/effects_cig_smoking/inde x.htm.

4. CHRISTOFARO G D et al. (2015) Higher screen time is associated with overweight, poor dietary habits and physical inactivity in Brazilian adolescents, mainly among girls. In European Journal of Sport Science. 16:4, 498-506. Available online: https://www.tandfonline.com/doi/abs/10.1080/17461391.2015 .1068868?fbclid=IwAR2Sy8

Qva2j_n3g2J4CJpsgd0x2CGYxUgo8JnYQy 0Qv6TnxUtXFaRUeVLhk.

5. GLOBAL RECOMMENDATIONS ON PHYSICAL ACTIVITY FOR HEALTH (2010) Switzerland: World Health Organization. Retrieved from: http://apps.who.int/iris/ bitstream/10665/44399/1/9789241599979_e ng.pdf.

6. ILIEVA I, IGNATOV G (2017) Individual and School Correlates of Adolescent Leisure Time Physical Activity in Quebec, Bulgaria. In: „Mircea cel Batran” Naval Academy Scientific Bulletin. [online]. 2017, vol. 2, no. 4. Available online: http://www.medscimonit. com/abstract/index/idArt/899816. ISSN 23928956.

7. ILLOW R, ROZANSKA D, REGULSKAILLOW B (2017) Prevalence of cardiovascular disease risk factors among pharmacy students from Wroclaw Medical University (Poland). In: Advances in Clinical and Experimental Medicine. [online]. 2017. vol. 26, no. 5. Available online: http://www.advances. umed.wroc.pl/en/article/2017/26/5/843/. ISSN 2451-2680.

8. MATEJOVICOVA B et al. (2015). Illegal Drug Use among Female University Students in Slovakia. In Medical Science Monitor: International Medical Journal of Experimental and Clinical Research. [online]. 2015. vol.9, no. 110. Available online: https://www.ncbi. nlm.nih.gov/pmc/articles/PMC4309727/pdf/ medscimonit-21- 254.pdf/. ISSN 1234-1010.
9. NOCIAR A (2014) Survey on drugs in students of higher education institutions in Slovakia: commissioned by The Independent. [online]. 1.ed. Bratislava: St. Elizabeth University of Health and Social Sciences. Available online: http://www.infodrogy.sk/indexAction. $\mathrm{cfm}$ ? module $=$ Library \&action $=$ Get -

File\&Do cumentID $=1115$. ISBN 8022408328.

10. SOCIAL AND ECONOMIC CONDITIONS OF THE LIFE OF STUDENTS OF HIGH SCHOOL IN EUROPE WITH A STOP TO THE RESULTS FOR THE SLOVAK REPUBLIC (EUROSTUDENT V 2012-2015). [online]. Available online: https://www.cvtisr. sk/buxus/docs/VS/eurostudent/eurostudent_v _web.pdf

11. TELFORD R M (2016) Why Are Girls Less Physically Active than Boys? Findings from the LOOK Longitudinal Study. In: Plos one. [online]. 2016. vol. 11, no. 3. Available online: https://www.ncbi.nlm.nih.gov/pmc/articles/PMC4784873/pdf/pone.0150041.pdf.

12. YOUNES F et al. (2016) Internet Addiction and Relationships with Insomnia, Anxiety, Depression, Stress and Self-Esteem in University Students: A Cross- Sectional Designed Study. [online]. 2016. vol. 11, no. 9. Available online: https://www.ncbi.nlm.nih. gov/pmc/articles/PMC5019372/.

13. WORLD HEALTH ORGANIZATION (2018) Adolescents: health risks and solutions. [online].2018. Available online: https:// www.who.int/news-room/fact- sheets/detail/ adolescents-health-risks-and-solutions.

14. WORLD HEALTH ORGANIZATION (2018) Physical activity. [online]. 2018. Available online: https://www.who.int/newsroom/facts-in- pictures/detail/physical-activity.

\section{Declaration}

The questionnaire in the submitted work was anonymous. At the beginning of the questionnaire respondents received information about the purpose of the questionnaire and its evaluation.

The authors have no conflict of interest. 